TITLE:

\title{
Quantitative analysis of neodymium, uranium, and palladium in nitric acid solution by reflection absorption spectrophotometry
}

\section{$\operatorname{AUTHOR}(S):$}

Fujii, Toshiyuki; Egusa, Souichirou; Uehara, Akihiro; Yamana, Hajimu; Morita, Yasuji

\section{CITATION:}

Fujii, Toshiyuki ...[et al]. Quantitative analysis of neodymium, uranium, and palladium in nitric acid solution by reflection absorption spectrophotometry. Journal of

Radioanalytical and Nuclear Chemistry 2013, 295(3): 2059-2062

\section{ISSUE DATE:}

2013-03

URL:

http://hdl.handle.net/2433/187114

\section{RIGHT:}

The final publication is available at link.springer.com; この論文は出版 社版でありません。引用の際には出版社版をご確認ご利用ください。; This is not the published version. Please cite only the published version. 
1 Short Communication

2

3 Quantitative analysis of neodymium, uranium, and palladium in nitric acid solution by

4 reflection absorption spectrophotometry

5

6 Toshiyuki Fujii, ${ }^{1 *}$ Souichirou Egusa, ${ }^{1,2}$ Akihiro Uehara, ${ }^{1}$ Hajimu Yamana, ${ }^{1}$ and Yasuji

7 Morita $^{3}$

8

91 Division of Nuclear Engineering Science, Research Reactor Institute, Kyoto

10 University, 2-1010, Asashiro Nishi, Kumatori, Sennan, Osaka, 590-0494, Japan

112 Graduate School of Engineering, Kyoto University, Kyoto daigaku-Katsura,

12 Nishikyo-ku, Kyoto 615-8530, Japan

13 Nuclear Science and Engineering Directorate, Japan Atomic Energy Agency,

14 Tokai-mura, Ibaraki-ken 319-1195, Japan

$16 *$ Author to whom correspondence should be addressed

17 tosiyuki@rri.kyoto-u.ac.jp

18 TEL: +81-72-451-2469, FAX: +81-72-451-2634

19

20 E-mail: tosiyuki@rri.kyoto-u.ac.jp 


\section{Abstract}

24 Quantitative analysis of $\mathrm{Nd}, \mathrm{U}$, or $\mathrm{Pd}$ in $3 \mathrm{~mol} \mathrm{dm}^{-3}(\mathrm{M}) \mathrm{HNO}_{3}$ was performed by 25 reflection absorption spectrophotometry at ultraviolet-visible-near-infrared 26 (UV/Vis/NIR) region. A sample chamber with optics for reflection measurement was 27 designed and attached to a UV/Vis/NIR spectrophotometer by optical fibers. The 28 reflection absorbance showed linear relations with concentrations of $\mathrm{Nd}, \mathrm{U}$, and $\mathrm{Pd}$ at 29 the absorbance region less than 0.1 . The quantitative analysis was found to be possible 30 for $3 \mathrm{M} \mathrm{HNO}_{3}$ solutions containing $[\mathrm{Nd}] \sim 0.2 \mathrm{M}$, $[\mathrm{U}] \sim 0.04 \mathrm{M}$, or $[\mathrm{Pd}] \sim 0.01 \mathrm{M}$.

32 Keywords

33 Absorption spectrophotometry; Reflectance; Neodymium; Uranium; Palladium; Nitric 34 acid. 


\section{Introduction}

Ultraviolet-visible-near-infrared (UV/Vis/NIR) absorption spectrophotometry is useful for quantitative analysis of complexes in solutions. For the purpose of process control in the nuclear fuel cycle, applicability of the absorption spectrophotometry is investigated $[1,2]$. The transmission absorption spectrophotometry with optical cells is commonly used for quantitative analysis. The method is highly precise, but basically off-line. The liquid sample is placed in an optical cell and its transmittance is measured. Flow cell is designed for online and in-line measurements of liquid stream. The liquid sample runs through an optical cell and the transmittance of the cell is measured. If the transmission system is installed to the nuclear fuel cycle, the system should equip the optical windows which contact with the radioactive solutions. Fragility of the optical windows may be problematic for avoiding a leak of the solution from the system. Without the optical windows, the transmittance of sample solution may be measured if a part of optics is directly immersed in the sample. An optical probe called "immersion probe", which consists of optical fibers and stainless steel (or hastelloy, titanium, quartz, and so on), is designed for this purpose. Direct contact of the solution with optical material is undesirable from the viewpoint of corrosion. If one considers high temperature systems like pyroprocessing or vitrification, the material damage becomes significant.

The reflection absorption spectrophotometry is known as a high-sensitive analytical method for chemical species adsorbed onto metallic surface [3]. The reflection technique is generally used in the infrared region [3]. A utilization of this technique at UV/Vis region has been reported for Langmuir monolayer [4]. A chemical species adsorbed onto the interface between dodecane and sulfuric acid has been analyzed by UV/Vis reflection absorption spectrophotometry [5]. An advantage of the 
reflection technique may be that the optics can be arranged above the solution surface and do not contact with the sample solution. Optical windows are not required for the container of the sample solution. It may be utilizable for online monitoring of liquid samples treated in the nuclear fuel cycle. We report the applicability of UV/Vis reflection absorption spectrophotometry for nitric acid solutions containing $\mathrm{Nd}, \mathrm{U}$, or $\mathrm{Pd}$, in which $\mathrm{Nd}$ and $\mathrm{Pd}$ are major fission product $(\mathrm{FP})$ elements of rare earth elements and platinum group elements, respectively.

\section{Experimental}

All chemicals were reagent grade. $\mathrm{Nd}\left(\mathrm{NO}_{3}\right)_{3} \cdot 6 \mathrm{H}_{2} \mathrm{O}$ was dissolved in $\mathrm{HNO}_{3}$ to prepare various concentrations of $\mathrm{Nd}(\mathrm{III})$ in $3 \mathrm{~mol} \mathrm{dm}{ }^{-3}(\mathrm{M}) \mathrm{HNO}_{3}$. Similarly, $\mathrm{UO}_{2}\left(\mathrm{NO}_{3}\right)_{2} \cdot 6 \mathrm{H}_{2} \mathrm{O}$ was dissolved in $3 \mathrm{M} \mathrm{HNO}_{3}$. Pd metal was dissolved in boiling 13.3 $\mathrm{M} \mathrm{HNO}_{3}$ [6], and then the solution was diluted with $\mathrm{H}_{2} \mathrm{O}$ to prepare $\mathrm{Pd}$ sample of $3 \mathrm{M} \mathrm{HNO}_{3}$.

The absorption spectrum was measured by using a UV/Vis/NIR spectrophotometer (JASCO, V-7200) at room temperature. A cubic sample chamber of $\sim 200 \mathrm{~mm}$ on a side was designed for reflection absorption measurement, whose plane view is shown in Fig. 1 schematically. The chamber was connected with the spectrophotometer by optical fibers. An aluminum mirror was set at the focal point. The incident angle of analytical light was designed to be $5^{\circ}$. The deuterium and tungsten light sources were switched at $350 \mathrm{~nm}$. The reflection intensity was measured in the wavelength range of 200-1000 nm at $1 \mathrm{~nm}$ intervals of $0.2 \mathrm{sec}$ integration time each. The band widths were $1 \mathrm{~nm}(200-800 \mathrm{~nm})$ and $5 \mathrm{~nm}(800-1000 \mathrm{~nm})$. The detectors, secondary electron multiplier (SEM) for UV/Vis region and PbS semiconductors for NIR region, were switched at $800 \mathrm{~nm}$. The obtained data was used as the blank 
spectrum. Then, the aluminum mirror was replaced by the sample solution in a quartz cell, and the reflectance was measured. A metal free $\mathrm{HNO}_{3}$ solution with the same acidity was also analyzed as reference. The transmission absorption spectrum was also measured for comparison.

\section{Results and discussion}

Neodymium possesses characteristic absorption bands in UV/Vis/NIR region [7]. The reflection intensity $(R)$ of water and $3 \mathrm{M} \mathrm{HNO}_{3}$ solution with or without $\mathrm{Nd}(\mathrm{III})$ was measured (Fig. 2a). A low signal-to-noise $(\mathrm{S} / \mathrm{N})$ ratio at around $800 \mathrm{~nm}$ is due to switching of detectors. The reflectance of water was measured to be $\sim 0.08 \%$ relative to that of the aluminum mirror. The reflectance of the aluminum mirror is commonly certified to be $\sim 90 \%$. The refractive indexes of water and quartz are 1.33 and 1.46 (Vis region, room temperature) [8]. From the Fresnel equations with the refractive indexes, for the system with $5^{\circ}$ incident and reflection angles, $93 \%$ of analytical lights transmit the quartz cell and $0.2 \%$ of the transmitted lights should be reflected at the water surface. The $R$ value of $0.08 \%$ means that $\sim 40 \%$ of the reflected lights are successfully collected at the inlet of optical fibers directed to the detector. The absorption band at $960 \mathrm{~nm}$ is attributable to the vibrations of $\mathrm{H}_{2} \mathrm{O}$. This is assigned to the combination transition $2 v_{1}$ $+v_{3}$, where $v_{1}$ is the symmetric $\mathrm{O}-\mathrm{H}$ stretch and $v_{3}$ the asymmetric $\mathrm{O}-\mathrm{H}$ stretch modes [9]. The absorption in $\mathrm{UV}$ region for $3 \mathrm{M} \mathrm{HNO}_{3}$ solution is due to the electron transition of $\mathrm{NO}_{3}^{-}[10,11]$.

The transmission absorbance $(A)$ is defined by the Lambert-Beer low, $A=-\log$ $\left(I / I_{0}\right)$, where $I_{0}$ and $I$ are the intensity of incident light and transmitted light, respectively. Similar to $A$, the reflection absorbance $\left(A_{\mathrm{R}}\right)$ is defined as, 


$$
A_{\mathrm{R}}=-\log \left(R / R_{0}\right)
$$

where $R_{0}$ is the reflection intensity measured for solvent $\left(3 \mathrm{M} \mathrm{HNO}_{3}\right)$ in quartz cell, and

$112 R$ is that containing solutes. The absorption spectra of $\mathrm{Nd}$ obtained are shown in Fig. $2 \mathrm{~b}$,

113 in which the transmission absorption spectrum reproduces the spectra reported for 114 nitrate systems [12-16]. The reflection absorption spectrum is similar to the transmission absorption spectrum but the absorbance $A_{\mathrm{R}}$ was found to be smaller than $A$. The $A_{\mathrm{R}}$ values in Fig $2 \mathrm{~b}$ are shown in Fig $2 \mathrm{c}$ as a function of $A$. At the absorbance 117 region from 0 to $0.1, A_{\mathrm{R}}$ is identical with $A$, while $A_{\mathrm{R}}$ is less sensitive at $A>0.1$. This is due to the detection limit of our analytical apparatus. The analytical light intensity is depreciated by connecting the sample chamber with optical fibers, and under this condition, the reflected light intensity of $R<0.08 \%$ is analyzed. For several absorption bands positioned by arrows shown in Fig. $2 \mathrm{~b}$, the dependence of $A_{\mathrm{R}}$ on $\mathrm{Nd}$ concentration was investigated. The result of $A_{\mathrm{R}} v s[\mathrm{Nd}]$ is shown in Fig. $2 \mathrm{~d}$. It is clear that, in the region $A_{\mathrm{R}} \leq 0.1, A_{\mathrm{R}}$ is proportional to $[\mathrm{Nd}]$. Quantitative analysis of $\sim 0.2 \mathrm{M}$ $\mathrm{Nd}$ in $3 \mathrm{M} \mathrm{HNO}_{3}$ is possible by employing the calibration lines for absorption bands at $460 \mathrm{~nm}$ and $679 \mathrm{~nm}$, whose coefficient of determination is better than 0.997. For quantitative analysis of $\mathrm{HNO}_{3}$ solutions with lower $\mathrm{Nd}$ concentration, $A_{\mathrm{R}}$ of strong absorption bands like $578 \mathrm{~nm}$ should be useful.

The $A$ and $A_{\mathrm{R}}$ values were measured for $\mathrm{U}$ in $3 \mathrm{M} \mathrm{HNO}_{3}$. The absorption spectra obtained are shown in Fig. 3a. The transmission absorption spectrum perfectly reproduced the pioneering work [17]. Uranium dissolved in $\mathrm{HNO}_{3}$ is $\mathrm{U}(\mathrm{VI})$ and forms uranyl ion, $\mathrm{UO}_{2}{ }^{2+}$. The electronic structure of $\mathrm{UO}_{2}{ }^{2+}$ has been studied in detail $[18,19]$.

132 The absorption bands possesses peaks via the stretching vibration of $\mathrm{O}=\mathrm{U}=\mathrm{O}$. The 
reflection absorption spectrum is similar to the transmission absorption spectrum. The $A_{\mathrm{R}}$ values are shown as a function of $\mathrm{U}$ concentration (Fig. $3 \mathrm{~b}$ ). Linear correlation is found in the region of $A_{\mathrm{R}}<0.1$. Quantitative analysis of $\sim 0.04 \mathrm{M} \mathrm{U}$ in $3 \mathrm{M} \mathrm{HNO}_{3}$ is possible by employing the calibration lines for absorption bands at $370 \mathrm{~nm}$ and $468 \mathrm{~nm}$, whose coefficient of determination is better than 0.994 . The curve of $A_{\mathrm{R}}$ for absorption bands at $415 \mathrm{~nm}$ can be used as an alternative of the calibration lines.

Palladium is known as one of the noble metal fission product elements in reprocessing of spent nuclear fuels. Its complexation characteristics in solvent extraction processes [20,21] are hence of interest. In our previous study, the complexation of $\mathrm{Pd}^{2+}$ with $\mathrm{NO}_{3}^{-}$was studied in detail by transmission absorption spectrophotometry [6]. The $A$ and $A_{\mathrm{R}}$ values of $\mathrm{Pd}$ in $3 \mathrm{M} \mathrm{HNO}_{3}$ obtained in the present study are shown in Fig. 4a. The transmission absorption spectrum reproduced the reported spectra $[6,22,23]$. The reflection absorption spectrum is similar to the transmission absorption spectrum. The $A_{\mathrm{R}}$ values are shown as a function of $\mathrm{Pd}$ concentration (Fig. 4b). Again, the linear correlation can be obtained in the region of $A_{\mathrm{R}}$ $<0.1$. Quantitative analysis of $\sim 0.01 \mathrm{M} \mathrm{Pd}$ in $3 \mathrm{M} \mathrm{HNO}_{3}$ is possible by employing the calibration line resulted from absorption intensities at the shoulder of absorption bands. In diluted $[\mathrm{Pd}]$ region, peak maximum can be used to prepare the calibration line.

Increasing the intensity of light source and the sensitivity of detectors improves the current system of reflection absorption spectrophotometry. Besides that, measurement of the surface of sample solution without using quartz cell should increase the reflectance light intensity. From the Fresnel equations, if we do not use the quartz cell, $\sim 2 \%$ of the transmitted lights are reflected at the solution surface. This means that the reflectance light intensity increases $\sim 10$ times more than that with the quartz cell. 
157 The nonflatness of liquid surface due to the surface tension and vibrations

158 (microvibrations) under the experimental circumstance is problematic. The former shifts

159 the focal point and the latter depresses the $\mathrm{S} / \mathrm{N}$ ratio. Installing autofocus device,

160 vibration-free system, and multiple detector may be required.

161

162

\section{Conclusions}

The UV/Vis/NIR reflection absorption technique for nitric acid solutions was developed.

Quantitative analysis of $\mathrm{Nd}, \mathrm{U}$, and $\mathrm{Pd}$ was possible for $3 \mathrm{M} \mathrm{HNO}_{3}$ solution containing

$\sim 0.2 \mathrm{M} \mathrm{Nd}, \sim 0.04 \mathrm{M} \mathrm{U}$, or $\sim 0.01 \mathrm{M} \mathrm{Pd}$. By using $A_{\mathrm{R}}$ of stronger/weaker absorption

bands, possible concentration range for quantitative analysis can be expanded. This technique may be applicable for analyzing radioactive solutions in nuclear fuel cycle.

\section{Acknowledgment}

170 The present study includes the result of "Development of High-level Liquid Waste

171 Conditioning Technology for Advanced Nuclear Fuel Cycle" entrusted to "Japan 172 Atomic Energy Agency" by the Ministry of Education, Culture, Sports, Science and Technology of Japan (MEXT).

\section{References}

176 [1] Relan GR, Dubey AN, Vaidyanathan S (1995) J Radioanal Nucl Chem 204:15

177 [2] Fujii T, Uda T, Fukasawa K, Uehara A, Sato N, Nagai T, Kinoshita K, Koyama

T, Yamana H (2012) J Radioanal Nucl Chem DOI: 10.1007/s10967-012-2008-3

179 [3] Greenler RG (1966) J Chem Phys 44:310

180 [4] Okamura E, Hasegawa T, Umemura J (1995) Biophys J 69:1142 
Anal Bioanal Chem 376:374

[6] Fujii T, Egusa S, Uehara A, Kirishima A, Yamagishi I, Morita Y, Yamana H

184 (2011) J Radioanal Nucl Chem 290:475

185 [7] Yatsimirskii KB, Davidenko NK (1979) Coord Chem Rev 27:223

186 [8] Hynes WM (2011) Handbook of chemistry and physics, 92th edn. CRC Press,

187 Boca Raton

188 [9] Phelan MK, Barlow CH, Kelley JJ, Jinguji TM, Callis JB (1989) Anal Chem $18961: 1419$

190 [10] Jones N, Thorn GD (1949) Canad J Res B 27:580

191 [11] Bayliss NS, Watts DW (1963) Aust J Chem 16:943

192 [12] Maeck WJ, Kussy ME, Rein JE (1965) Anal Chem 37:103

193 [13] Choppin GR, Henrie DE, Buijs K (1966) Inorg Chem 5:1743

194 [14] Abrahamer I, Marcus Y (1968) J Inorg Nucl Chem 30:1563

195 [15] Janssens-Maenhout G, Nucifora S (2007) Nucl Eng Design 237:1209

196 [16] Fujii T, Okude G, Uehara A, Sekimoto S, Hayashi H, Akabori M, Minato K, 197 Yamana H (2011) J Radioanal Nucl Chem 288:181

198 [17] Betts RH, Michels RK (1949) J Chem Soc S286

199 [18] M M Glynn SP, Smith JK (1961) J Mol Phys 6:164

200 [19] Denning RG (1992) Struct Bonding 79:215

201 [20] El-Reefy SA, Daoud JA, Aly HF (1992) J Radioanaly Nucl Chem 158:303

202 [21] Fujii T, Yamana H, Watanabe M, Moriyama H (2001) J Radioanal Nucl Chem $203 \quad 247: 435$

204 [22] Jørgensen CK, Parthasarathy V (1978) Acta Chem Scand A32:957

205 [23] Frias EC, Pitsch HK, Ly J, Poitrenaud C (1995) Talanta 42:1675 


\section{Figure captions}

208 Fig. 1 Optical alignment of sample chamber for reflection absorption measurement.

209 Fig. 2 Reflection absorption spectra of $\mathrm{Nd}(\mathrm{III})$ in $3 \mathrm{M} \mathrm{HNO}_{3}$. a Reflectance of $\mathrm{H}_{2} \mathrm{O}, 3$

$210 \mathrm{M} \mathrm{HNO}_{3}$, and $0.04 \mathrm{M} \mathrm{Nd}(\mathrm{III})$ in $3 \mathrm{M} \mathrm{HNO}_{3}$. b Transmission absorbance $A$ and

211 reflection absorbance $A_{\mathrm{R}}$ for $0.04 \mathrm{M} \mathrm{Nd}(\mathrm{III})$ in $3 \mathrm{M} \mathrm{HNO}_{3}$. Absorbances at wavelengths

212 positioned by arrows were used in Fig. 2 d. c $A_{\mathrm{R}} v s A$ d Dependence of $A_{\mathrm{R}}$ on $\mathrm{Nd}$ (III)

213 concentration.

214 Fig. 3 Reflection absorption spectra of $\mathrm{U}(\mathrm{VI})$ in $3 \mathrm{M} \mathrm{HNO}_{3}$. a Transmission absorbance $215 A$ and reflection absorbance $A_{\mathrm{R}}$ for $0.0075 \mathrm{M} \mathrm{U}(\mathrm{VI})$ in $3 \mathrm{M} \mathrm{HNO}_{3}$. Absorbances at 216 wavelengths positioned by arrows were used in Fig. 3b. b Dependence of $A_{\mathrm{R}}$ on U(VI) 217 concentration.

218 Fig. 4 Reflection absorption spectra of $\mathrm{Pd}(\mathrm{II})$ in $3 \mathrm{M} \mathrm{HNO}_{3}$. a Transmission absorbance $219 A$ and reflection absorbance $A_{\mathrm{R}}$ for $0.001 \mathrm{M} \mathrm{Pd}(\mathrm{II})$ in $3 \mathrm{M} \mathrm{HNO}_{3}$. Absorbances at 220 wavelengths positioned by arrows were used in Fig. 4b. b Dependence of $A_{\mathrm{R}}$ on $\operatorname{Pd}(\mathrm{II})$ 221 concentration. 


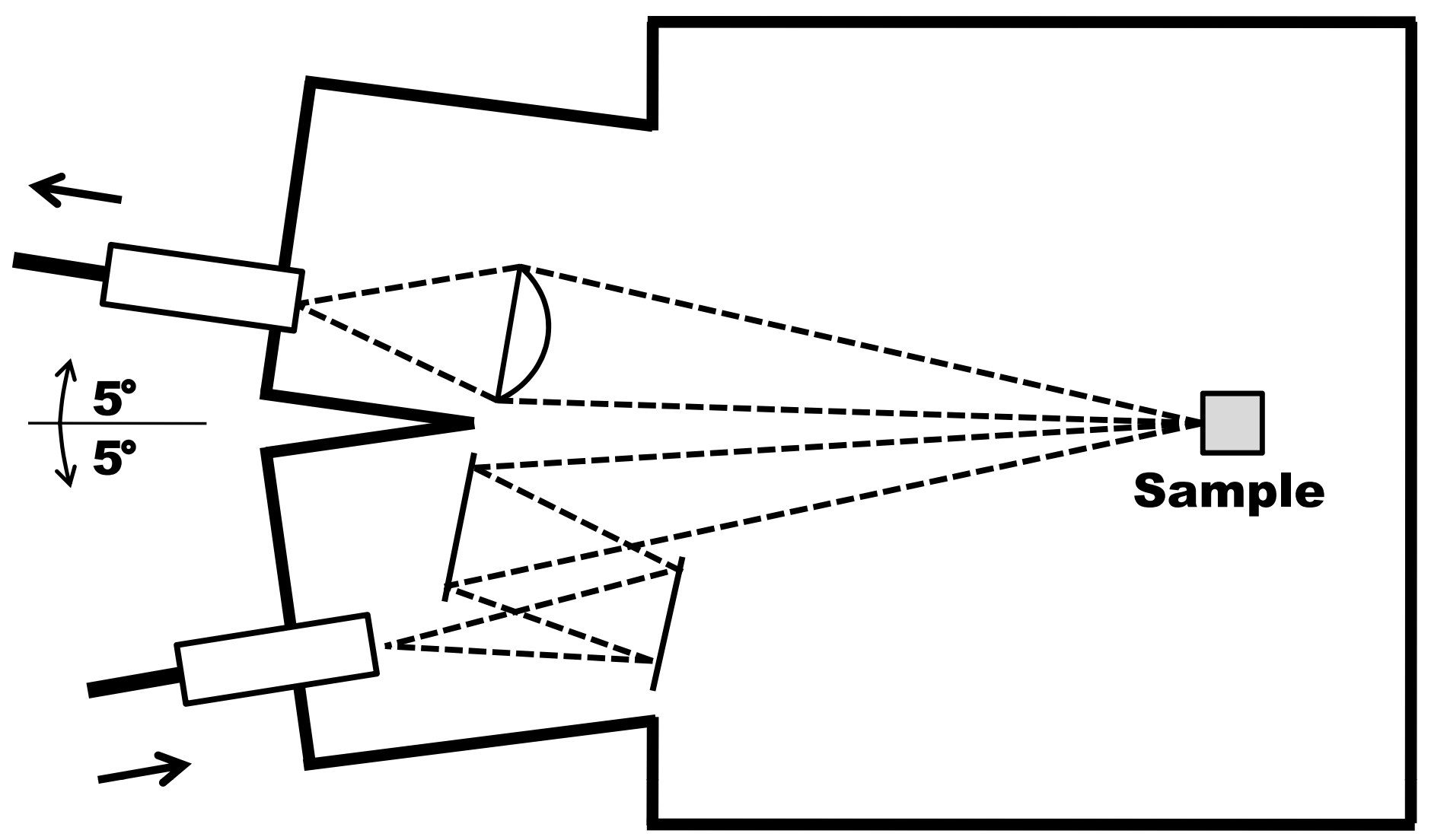



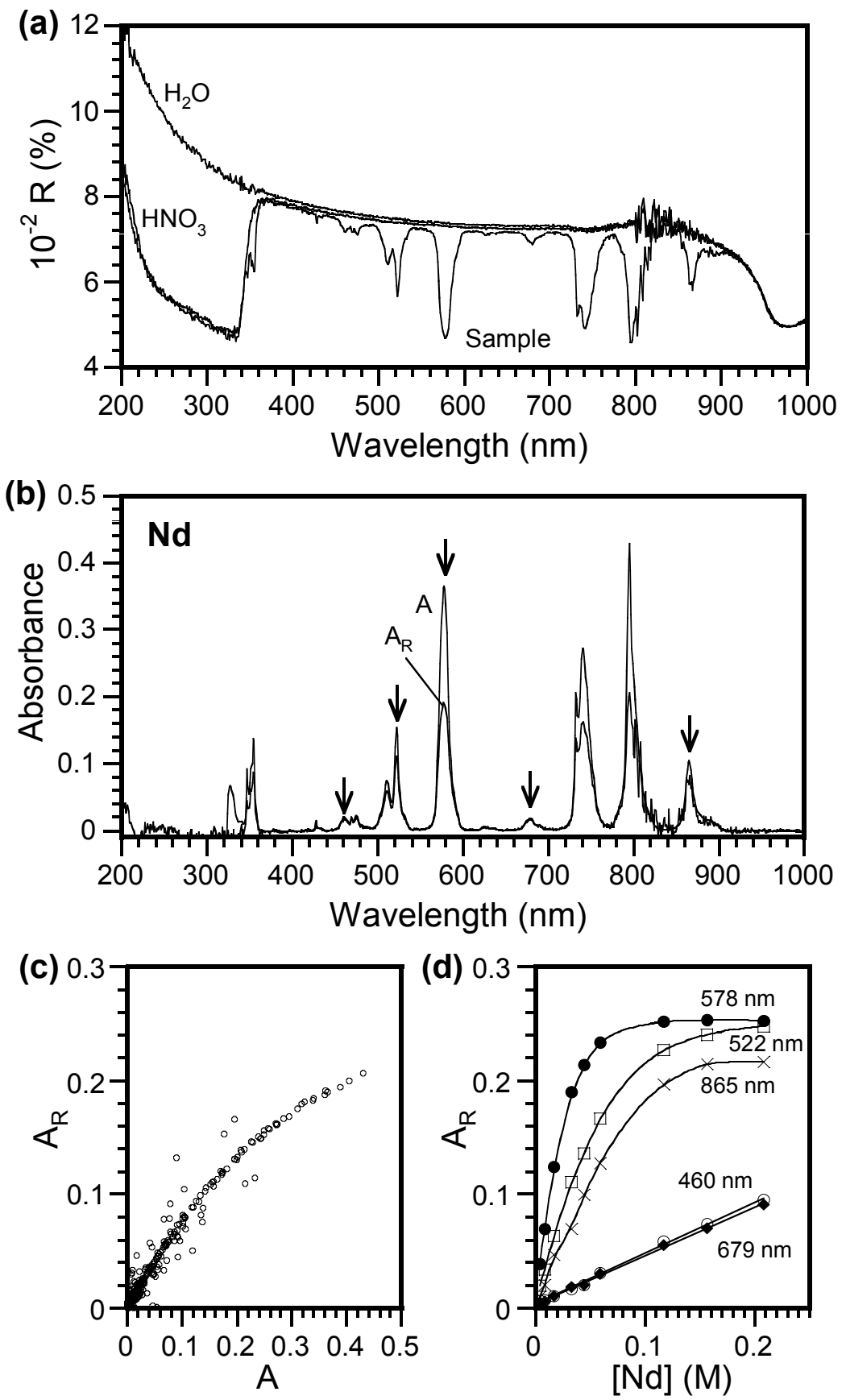

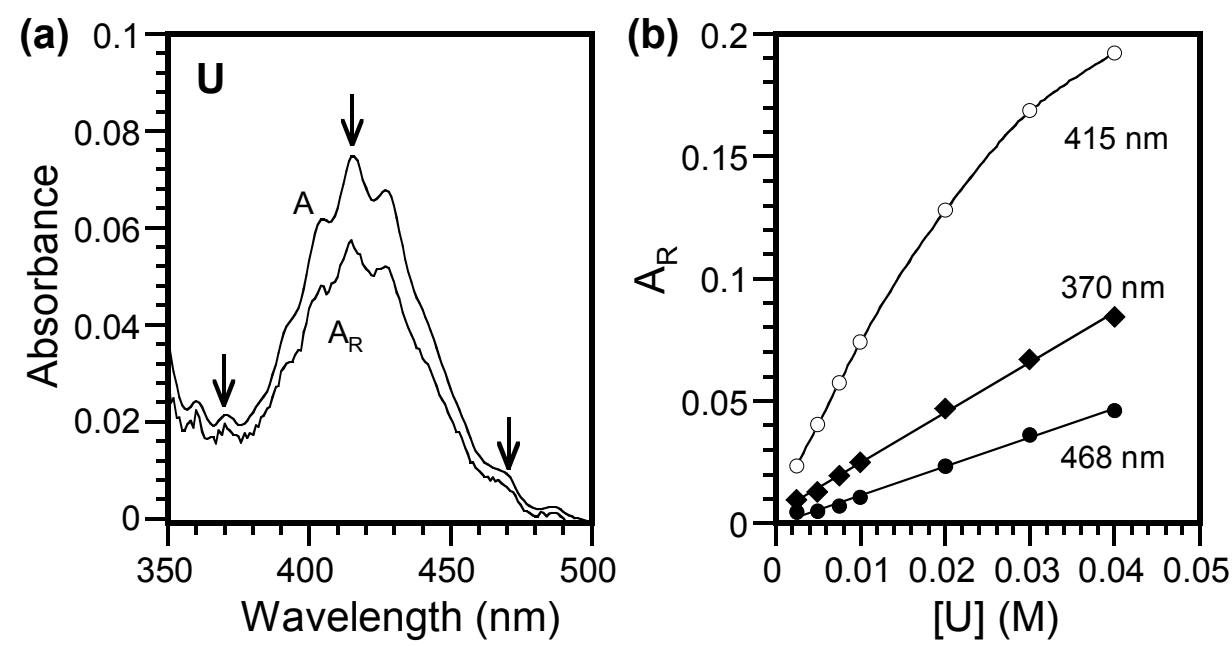

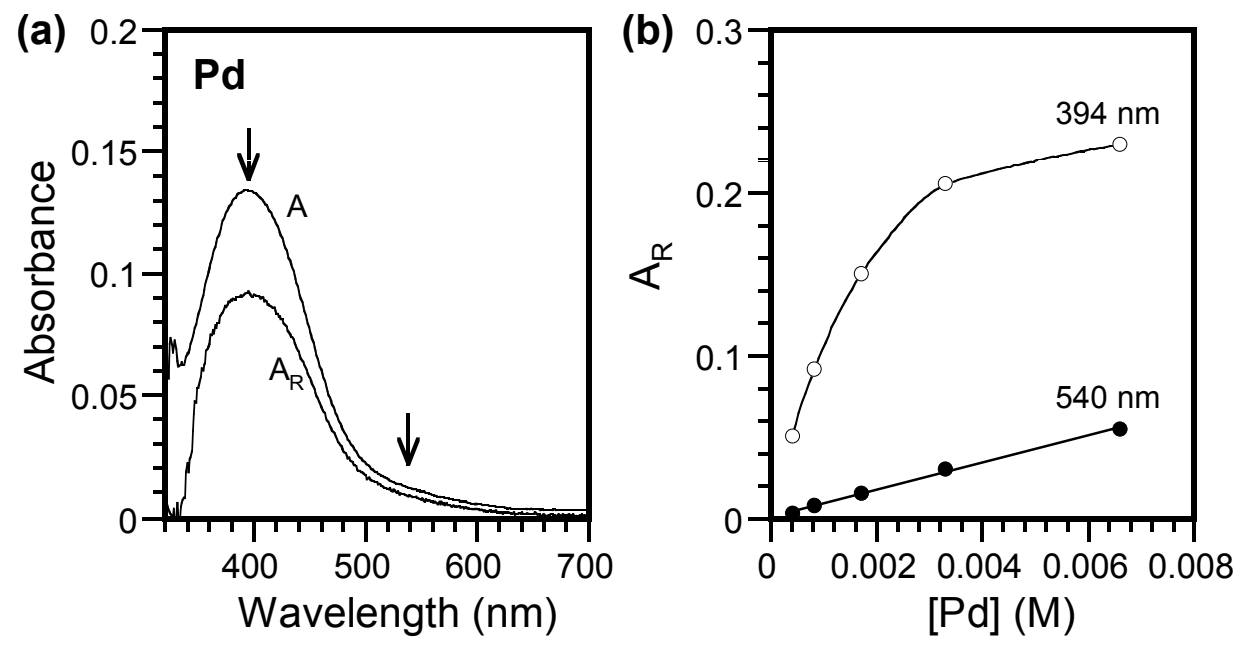